\title{
Avaliando a memória por meio da visualização da imagem de rostos
}

\section{Carla Femanda FereiraRodiguss - UniversidadeSãoFranisco, Itatiba, SãoPaulo, Brasil}

Leme, I. F. A. S., Rossetti, M. O., Pacanaro, S. V., \& Rabelo, I. S. (2011). TestedeMemóna Visual deRostos- MVR. São Paulo: Casa do Psicólogo.

O Teste de Memória Visual de Rostos (MVR) foi criado por Nicolas Seisdedos, sendo que a tradução do manual original em espanhol foi realizada por D enílson Luís dos Santos, e adaptado para o Brasil pela equipe do D epartamento de Pesquisa e Produção de Testes da Editora Casa do Psicólogo. O MVR avalia a capacidade da pessoa recordar rostos e informações associadas a eles (nomes, sobrenomes, profissão, localização, dentre outros) por meio da visualização de imagens. É um instrumento que avalia a memória de curto prazo, sendo necessário haver um intervalo de tempo entre a apresentação dos estímulos e 0 exame de seus conteúdos, no qual devem-se introduzir itens distrativos para que a atenção fique centrada em outras tarefas, como a aplicação de outros testes ou técnicas.

O MVR pode ser aplicado individual ou coletivamente e é composto por duas partes. Na primeira, é apresentada a ficha de memorização com 12 figuras de rostos, dos quais seis masculinos e seis femininos, e cada figura possui informações dos rostos, como nome, sobrenome, profissão e o lugar de origem de cada pessoa (cada informação é única, não havendo repetição). A segunda parte corresponde ao caderno de aplicação, que é composto por 20 itens distribuídos em duas páginas. Na primeira, são apresentados três itens pictóricos, cada item mostra quatro rostos de homens e mulheres, alguns dos quais aparecem na ficha de memorização, e oito itens na forma de questionamentos (verbal) sobre conteúdos da ficha de memorização. $\mathrm{Na}$ segunda página, há três itens pictóricos com mais seis itens de conteúdo diverso. No caso de ser necessária a reaplicação do instrumento, os autores instruem que esta se dê com o intervalo mínimo de 21 dias da aplicação anterior.

Para ser realizada a padronização brasileira do MVR foram necessárias algumas adaptações. Desse modo, nomes, sobrenomes, profissões e cidades foram adaptados para o contexto brasileiro. A amostra no estudo de padronização foi composta por 1.130 pessoas, com idade média de 27,95 anos ( $\mathrm{DP}=9,23)$, variando de 18 a 80 anos. Do total, 55,8\% era do sexo masculino, a maioria (66\%) residindo no estado de São Paulo, seguido do estado do Amazonas (18,8\%). Com relação à escolaridade, a maior parte dos participantes $(73,7 \%)$ cursava ou havia concluído o curso superior.

Quanto às evidências de validade, foi realizado um estudo relativo ao desenvolvimento e verificado que a média no MVR tende a diminuir com 0 avanço da idade, o que é esperado em testes que avaliam a memória. Quanto ao sexo, verificou-se que há diferença significativa na pontuação de homens e mulheres e que 0 nível de escolaridade também interfere significativamente no desempenho do teste, sendo que à medida que a escolaridade aumenta, tende a aumentar também a pontuação no MVR. Foi constatada evidência de validade convergente entre 0 MVR e o Teste Pictórico de Memória - TEPIC (Rueda \& Sisto, 2007) e entre o MVR e os subtestes da Escala Wechsler de Inteligência para adultos - WAIS-III (Nascimento, 2004) relacionados à avaliação de memória. Foi encontrada evidência de validade de critério entre grupos de dependentes e nãodependentes químicos, como também em um grupo que possuía Síndrome de Down e outro sem a síndrome.

Os itens do teste em questão foram analisados por meio do modelo de Rasch, sendo verificada uma boa adequação ao modelo, contudo alguns dos participantes apresentaram índices de habilidade superiores aos índices de dificuldade dos itens. Outro estudo de validade foi realizado pelo processo de resposta em que foram comparados os dois grupos de itens, ou seja, o grupo de itens pictóricos que utilizam desenho dos rostos e o grupo de itens verbais que utilizam informações associadas a cada rosto, verificando-se que as respostas aos itens não-pictóricos diferem significativamente dos pictóricos e que os nãopictóricos são mais difíceis. Por fim, foi realizado um estudo de validade referente à estrutura interna por meio da análise do Funcionamento D iferencial do Item (DIF) para verificar se havia diferença entre os itens respondidos por homens e mulheres. Três itens favoreceram ao sexo masculino e 4 itens ao sexo feminino. Os autores do teste, então, optaram por manter os itens sem modificações, uma vez que houve um equilíbrio no número dos que favoreceram a um sexo em detrimento de outro.

A precisão do MVR foi calculada por meio da análise da consistência interna utilizando-se 0 coeficiente alfa de Cronbach e o método das duas metades de Spearman-Brown. Os índices para amostra geral e considerando os grupos separadamente em função do sexo, nível de escolaridade e faixa etária foram considerados satisfatórios. Foi realizado 
também um estudo de precisão pelo método testereteste e encontrada uma precisão moderada por esse método.

Para a obtenção da Pontuação Direta (PD) no teste, o psicólogo deve utilizar o crivo de correção com os acertos e depois com os erros. 0 número de erros (E) deve ser dividido por 3 e subtraído do número de acertos (A), como visualizado na fórmula a seguir: $\mathbf{P D}=\mathbf{A}-\mathbf{( E / 3 ) . ~ A p o ́ s ~ o ~ c a ́ l c u l o ~ d a ~ P D ~ , ~ o ~ e x a m i n a d o r ~}$ deverá localizar 0 percentil nas tabelas normativas, sendo que o MVR possui normas de interpretação por faixa etária, sexo e geral, por nível de escolaridade e para classificação de policiais militares e amostra geral.

Os autores do Teste de Memória Visual de Rostos, que foi aprovado em 2010 para o uso profissional pelo SATEPSI (http:// www2.pol.org.br/ satepsi/ sistema/ admin.cfm), declaram que 0 teste pode ser utilizado em diversos contextos em que é necessário avaliar a memória, dentre eles, avaliações neuropsicológicas, educacional, organizacional, trânsito, porte de armas, etc. É importante lembrar que a amostra de padronização é predominantemente do estado de São Paulo e que a maioria dos participantes cursavam ou já possuíam 0 nível superior de ensino. Com isso, deve-se ponderar quanto à utilização desse instrumento principalmente com pessoas de nível educacional muito baixo.

\section{Referências}

Nascimento, E. (2004). Escala deIntdigênaia Wehder para Adultos São Paulo: Casa do Psicólogo.

Rueda, F. J. M., \& Sisto, F. F. (2007). Teste Pictóico de Memóna - TEPIC-M São Paulo: Vetor Editora Psicopedagógica Ltda.

Sobre a autora:

Carla Femanda Ferreira-Rodrigues é psicóloga (UFPB), mestre em Psicologia (UFRN) e doutoranda pelo Programa de Pós-Graduação Strido Sensuem Psicologia com área de concentração em Avaliação Psicológica, da Universidade São Francisco. É bolsista CAPES.

Contato com a autora:

Rua Francisco Glicério, 10, apt. 84 - Centro - CEP 13250-330 - Itatiba-SP, Brasil.

E-mail: carlafernandafr@gmail.com 